\title{
Assisted vs. Guided Handwriting: a current approach to an old problem*
}

\author{
NikOLAOS KaLANTZIS \\ Chartoularios Ltd. Laboratory of Questioned Document Studies, Athens, Greece \\ LEONIDAS-D. GIDOGIANNOS
}

Chartoularios Ltd. Laboratory of Questioned Document Studies, Athens, Greece

\section{Introduction}

As forensic handwriting \& document examiners we are trained to examine \& compare "normal" handwriting. "Normal" handwriting meets the criteria set by our methodology in order to be compared \& evaluated (e.g. consistency etc). What happens with "not-so-normal" handwriting?

Grapho-kinetic problems include:

- Parkinson's Disease (permanent)

- Alzheimer's Disease (permanent)

- Partial or total blindness (permanent)

- Drug abuse (temporary)

- Alcohol abuse (temporary)

- Two very problematic categories of handwritten product are:

1. Assisted Handwriting

2. Guided Handwriting

3. Supported Handwriting

* The case report were removed from the text version as the case has not yet settled in court. 
The need to distinguish among the three products is evident. Assisted handwriting suggests consent from the part of the original writer. Guided handwriting could involve unwilling or incoherent writer being "manipulated" by the guide. Supported handwriting involves simple support of the writing hand.

As Plamondon ${ }^{1}$ mentions, there are three main stages of writing, the grapheme (the concept of the letter without a specific form), the allograph (specific representation for a specific type of letter) and the graph which represents the sequence of necessary movements to form a letter.

In the process of learning and coming of age, the muscles of the arm are "trained" and acquire the "habit" of writing. This stage in combination with the "mental" stage results in the uniqueness of writing. Disturbances in any stage result in problems in the uniqueness process mentioned above.

When comparing handwriting or signatures the necessary condition is the stability of the sample writing. Consistency in the specimen writer's material will enable the examiner to evaluate his findings and reach a conclusion concerning the authenticity of the questioned writing.

\section{Background}

In the problematic situations mentioned our main difficulty is consistency in the original handwriting. Clark Sellers in his paper " ${ }^{2}$ "Assisted \& Guided signatures" describes:

- A signature in which abnormalities occur because the hand of the genuine writer has been assisted or guided may be erroneously attacked as a forgery.

- On the other hand, a forged signature may be incorrectly accepted as genuine on the grounds that the abnormalities are due to its having been written while another person guided the hand of the writer.

From this point on the following terminology will be used:

1 Brault \& Plamondon: JoOP 1983; 56. Inferring Personal Qualities Through Handwriting Analysis.

2 Sellers C., "Assisted and guided signatures", The Journal of Criminal Law, Criminology and Police Science, vol. 53 (1962). 
$-1^{\text {st }}$ person: the original writer that experiences some sort of problem and therefore needs assistance in order to complete his handwriting. $-2^{\text {nd }}$ person: the person either assisting (assisted writing) or guiding (guided writing).

- Assisted handwriting, or supported handwriting (assisted hand): involves any form of writing in which the $2^{\text {nd }}$ person carries out supporting/assisting functions by facilitating the conditions of writing (e.g. support of elbow or repositioning of hand at the beginning of the line), with simple support of part of the hand or the body, without interfering to the writing movement itself.

Guided handwriting, or directed handwriting, (guided hand): involves any form of writing in which the $2^{\text {nd }}$ person assumes a prime role in the action of writing leading and directing the hand of the $1^{\text {st }}$ person, and affecting the writing procedure. In this category belong all the cases where the $1^{\text {st }}$ person cannot write or sign independently on its own without the intervention of another person.

Concerning the characteristics of distressed writing, C. Sellers describes restricted movements, tremulous, hesitant strokes, variations or differences from the normal genuine signatures. But aren't these characteristics of forgery?

Investigation of either assisted or guided handwriting is de facto problematic, and it is not easy to locate "candidates" for such studies, let alone start collecting samples for a proper research project. As a result theoretical models follow a straightforward line of logical thinking that is not necessarily true.

The available relevant English literature mainly includes the following three publications:

- Hecker M.R., "The taking of handwriting samples in relation to cases of claimed assistance in writing", Journal of Forensic Document Examination, vol. II, Numbers 1\&2 (Fall 1988);

- Jones D.G., "Guided hand or forgery?", Journal of the Forensic Science Society, vol. 26 (1986);

- Sellers C., "Assisted and guided signatures", The Journal of Criminal Law, Criminology and Police Science, vol. 53 (1962).

What is the most obvious characteristic? For guided handwriting: characteristics of the $2^{\text {nd }}$ person interfere in the resulting handwriting 
(Kelly/ Jones). Easy to guess, but is this a distinct characteristic of guided handwriting or is it found in assisted handwriting as well?

Many assume that in guided handwriting the $1^{\text {st }}$ person is passive (true) in contrast with assisted handwriting when the $1^{\text {st }}$ person is active (conditional). They also assume that this has a straightforward effect in the resulting handwriting.

Furthermore it is suggested that if the $1^{\text {st }}$ person is not passive then there is going to be a continuous "struggle" between the two writers and the resulting handwriting will be a fusion of both writing styles and characteristics. This assumption appears logical but is not necessarily true.

C. Sellers suggests that in guided signatures the dominant hand usually registers the greater number of writing characteristics, hence such a signature may include more characteristics of the guider ( $2^{\text {nd }}$ person) than of the guided $\left(1^{\text {st }}\right.$ person $)$. If the hand of the genuine writer $\left(1^{\text {st }}\right.$ person) is merely steadied and not actually guided, the characteristics may be entirely is. This is not supported with any form of study.

The only published research in English has been done by Hecker ${ }^{3}$. It involves a case regarding the question of guided versus assisted handwriting on a last will $\&$ testament. The court reconstructed the situation in the courtroom. Throughout the reconstruction the description of the person that assister/guided the testator was followed.

In the court reconstruction two main tests took place.

a. The test person ( $1^{\text {st }}$ person) was instructed to remain completely passive and not to counteract the writing helper's impulses ( $2^{\text {nd }}$ person).

b. The test person ( $1^{\text {st }}$ person) was asked not to remain passive, but to try to shape letters against the guider's impulses ( $2^{\text {nd }}$ person).

The results were quite interesting as comparisons between the questioned writing and that of the deceased person and between the test person's "guided" and normal writing do not show any considerable effects of the guided person's writing habits on the bi-personal product. Rather, the handwriting pattern of the guider is dominant in both cases.

3 M.R., Hecker, "The taking of handwriting samples in relation to cases of claimed assistance in writing”, Journal of Forensic Document Examination, vol. 2, Numbers 1\&2 (Fall 1988). 
It has to be taken into account that a healthy strong middle-aged man in the recreation, and writer specific impulses when recognizable at all are of the $2^{\text {nd }}$ person.

Therefore, the writing tests appear to justify the conclusion that the active part played by the guided subject is not reflected in his handwriting pattern, but merely results in a larger degree of illegibility and disturbance in the writing. These results are quite different from what one would expect - the $1^{\text {st }}$ persons characteristic are not at all detectable.

Certainly not easy but Manfred Hecker's study suggests that characteristics of the $1^{\text {st }}$ person's handwriting are expected in assisted handwriting, while characteristics of the $1^{\text {st }}$ person's handwriting are not expected at all in guided handwriting (regardless of whether the $1^{\text {st }}$ person was active or passive). Still there are no easy tools to distinguish complete forgeries (no participation from $1^{\text {st }}$ person).

The QDE examiner has to treat the subject on a case by case basis, taking into account all the relevant literature but also the special conditions of each case (i.e. witness accounts on how the hand was assisted or guided).

To address the lack of relevant research \& literature, a study was carried out in the University of Central Lancashire at Preston, in order to address such issues. The study aimed to investigate the extent of alteration hand guidance has on a person's signature.

Reviewing the aforementioned literature, Sellers ${ }^{4}$ :

- Addressed some of the difficulties occurring when examining guided signatures.

- Detected usually occurring abnormalities that might confuse a genuine guided signature as forgery or vice versa.

- Reported the impossibility of two persons writing simultaneously, because of the writing conflict that occurs.

- The legal question regarding the validity of the signature has to do with the mental capacity and will of the person being guided.

- Tremulous, hesitant strokes can be due to guidance, but can also be due to forgery.

4 Sellers, C. (1962). “Assisted and guided signatures”, The Journal of Criminal Law, Criminology and Police Science, vol. 53. 
On another publication Folley ${ }^{5}$ :

— Studied 53 participants, average age: 81

- Addressed other factors like medication, weakness, bad eyesight

- Made the point that in most cases exemplars/standards for comparison cannot be obtained because of the condition of the person in need of guidance.

- Highlighted the importance of considering the role of the assisting party.

- The assistance may vary and the result will be different. Gave two extremes.

- Because of the movement restriction, the proportionate heights of the letters, lateral spacing, size and alignment were affected.

And finally Hecker ${ }^{6}$ :

- Argued that usually considerable periods of time elapse between the drafting of a will and the examination by the expert, making it difficult to find authentic reference samples - maybe the testator has died.

- Stressed the limitations of the experts regarding medical diagnosis and the need for doctor consult in case of medication by the testator.

- Proposed that courts should order a demonstration of the alleged writing conditions. What was the "help" provided as a witness might claim.

- Presented the conditions and results of a court ordered test, in which the guided person was tested having both a passive and an active role.

— Different assisting positions were tested.

- When the test person was instructed in a test not to remain passive but to take part in the writing, the results suggested that the handwriting pattern does not show any creating impulses of the guided writer in the handwriting

The aim of the present study was to determine the extent (if any) a guided signature contains features from the guider or guided writer.

5 Foley FG and Kelly JH. Guided hand signature research. Journal of Police Science and Administration 1977; 5: 227

6 Hecker, M.R. (Fall 1988). 'The taking of handwriting samples in relation to cases of claimed assistance in writing' Journal of Forensic Document Examination, Volume 2 Numbers $1 \& 2$ 
Additionally, whether a link existed between a writer (guider/guided) and a category of signatures (guided/supported).

Therefore the objectives of the study were:

(i) To establish whether the features of guider or guided are found throughout the supported and guided signatures.

(ii) To establish which features are the most representative in identifying a relationship between the writers in both supported and guided signatures.

\section{Methods}

Concerning the collection of samples, the signatures for this study were obtained from 14 participants, 13 of them were right handed and one left-handed. The participants chosen were of mixed gender, between 20 and 40 years old, without any motor or cognitive issues, so that their handwriting style is fully developed and not deteriorated.

The participants were asked to provide normal samples of their signature and samples while their signing hand was either supported or guided. Only one guider was used in this research in order to monitor the effects of interference on the signatures and to avoid subjective evaluation of the instructions. This way consistency, regarding the force applied, was obtained throughout the different participants whilst supporting or guiding them.

The characteristics that were selected, identified and compared throughout the study are:

(I) Slope: The slope of the letters in the signature was categorized as: vertical, backward or forward. If the top part of the signature was leaning to the left it was categorized as backward and vice versa for forward. 


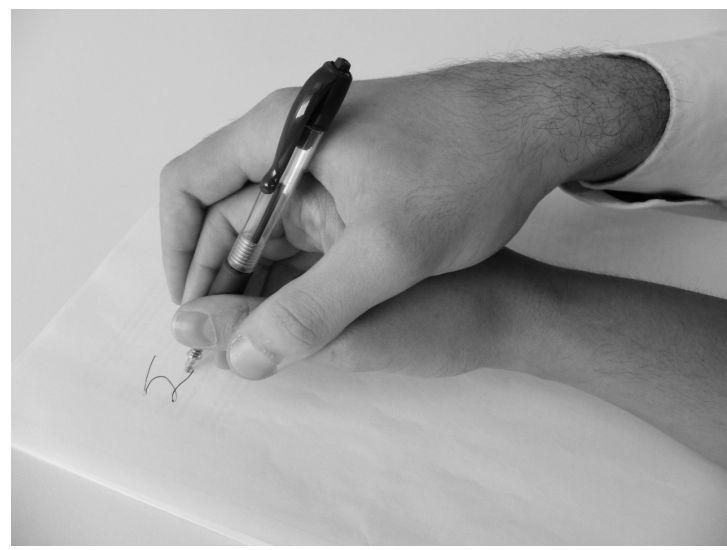

Figure 1. Clasp used for collection of samples

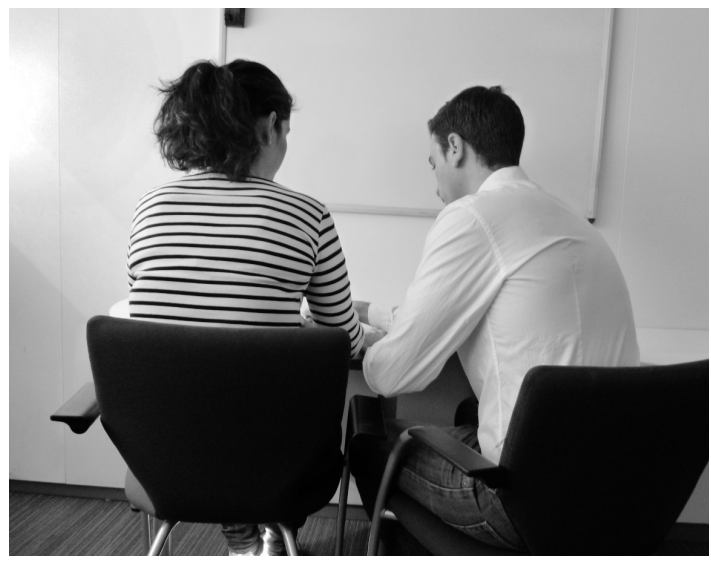

Figure 2. Positioning used for collection of samples

(II) Size: The size of the signatures was separated into average, small or large; it was examined as a relative value considering the length and width of the signature as well as the space it occupied in the preprinted boxes. It was also examined taking into consideration the relationship with the guided and guider's normal signatures, as well as considering the number of characters used (e.g. signatures with more letters although longer would not be considered larger than others with 
less letters). It should be noted that the subjects received no instruction on whether they should fill the preprinted boxes or not with the size of their signature, which might account as a limiting factor in the examination of this feature.

(III) Fluency: The fluency was determined as poor, average or good. It was expected that the fluency would be good for the normal, unaffected signatures of both the guider and the guided as further discussed in the discussion section.

(IV) Pen lifts: The amount of pen lifts were categorized as none, few or many. This variable was expected to show the personal preference of the writer on lifting the pen while writing, but also an increase in pen lifts might have shown a decrease in fluency. For example when guiding a signature, the pen lifts might increase because of the effort that is exercised by the guider to write while holding another person's hand.

(V) Length: The length was categorized as average, short or long. This variable was measured by taking into consideration the length of the signature regardless of the number of characters used. However, similarly to the size factor, no instructions were given to the subjects on whether they should try to fill the preprinted boxes with their signature or simply use what they consider an average size; this might account as a limiting factor on the importance of findings regarding length.

(VI) Line positioning: The line positioning of signatures was separated as middle, low or high, considering the preference of each writer in positioning the signature on the vertical axis of the preprinted boxes.

The following three features, for practicality reasons, were expressed only in comparison with the guider and guided writer signatures when supported or guided, because the evaluation is relative and not an absolute one (e.g. it is impossible to say there is "a lot of ratio"; instead, the comparison was direct).

(VII) Spacing: Spacing was categorized as same as guided, same as guider or no similarity. Spacing is a factor that was examined similarly to ratio, i.e. if the size increases the spacing increases too, but if this increase is proportional to the increase of size, it is considered unaltered.

(IIX) Ratio: Ratio was categorized as same as guided, same as guider or no similarity. This variable examined the internal proportions (e.g. the relation of small letters to larger ones) of the supported and guided signa- 
tures and their relation to the guider and guided specimens. Despite the change in size, fluency or jerkiness, ratio usually remains unaffected and thus considered a feature that provides strong evidence for the identification of a writer.

(IX) Letter construct: The way characters were constructed was categorized as same as guided, same as guider or no similarity. This is probably the most important feature for identifying a writer since the letter construction is the best way to compare two writers.

\section{Results and discussion}

The results were statistically treated through the " $\mathrm{R}$ " program, and an ANOVA test was performed.

When examining the relationship between the signature and the guided writers, the statistical test showed a significant difference $(z=7.75)$, revealing that it is $\mathbf{1 4 . 2}$ times more likely the supported specimens being similar to the guided writers, rather than the guided ones being similar to the guided writers.

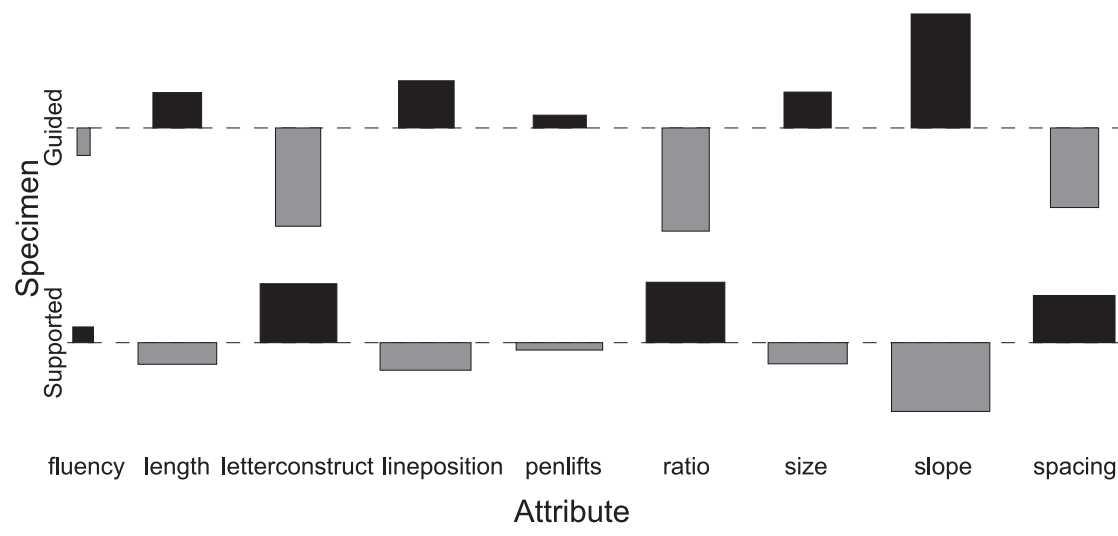

Figure 3. Association plot depicting the relationship of supported and guided signatures with the guided writers. The slope, letter construct, ratio and spacing show significant differences 
Assisted vs. Guided Handwriting: a current approach to an old problem

131

\begin{tabular}{|l|l|}
\hline Supported Signature & Guided Signature \\
\hline Guided writer & \\
\hline & Guider \\
\hline
\end{tabular}

Figure 4. Example of sample writing

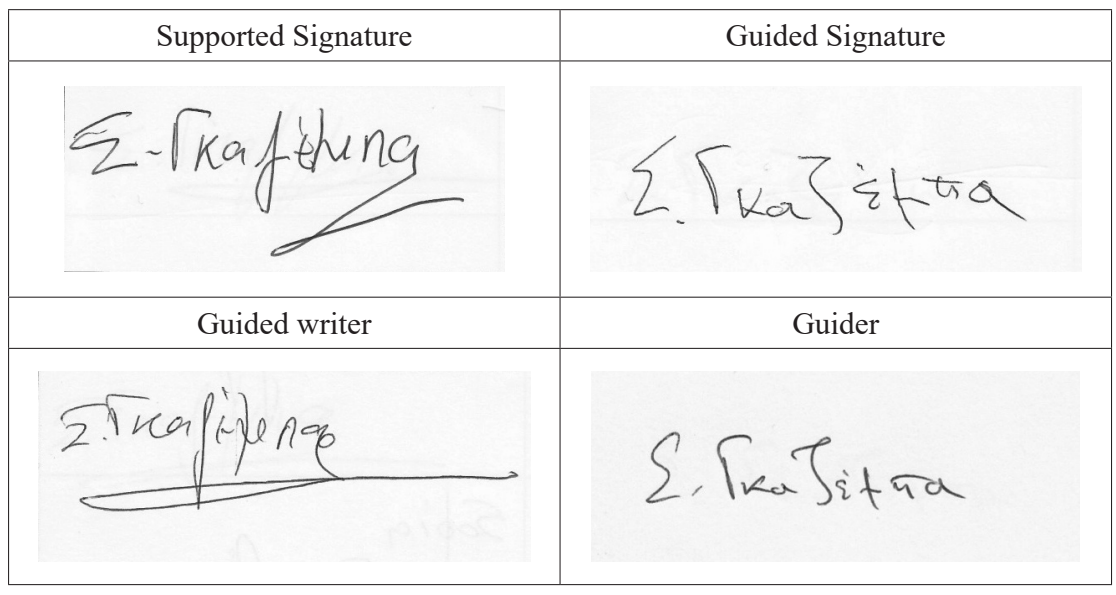

Figure 5. Example of sample writing

\begin{tabular}{|l|c|c|}
\hline \multicolumn{1}{|c|}{ Feature } & Matching subjects & Notes \\
\hline Slope & $11 / 14(1)$ & $\begin{array}{c}\text { The uncomfortable position (clasping) } \\
\text { has affected the slope in some occasions }\end{array}$ \\
\hline Size & $8 / 14(1)$ & $\begin{array}{c}\text { In some of the supported signatures the } \\
\text { size grows by a factor of } 1 \text { or even } 2\end{array}$ \\
\hline
\end{tabular}

Now Kodyfikacja Prawn Karnego 44, 2017

(C) for this edition by CNS 


\begin{tabular}{|l|c|c|}
\hline Fluency & $1 / 14(0)$ & Getting worst at supported signatures \\
\hline Pen lifts & $12 / 14(1)$ & $\begin{array}{c}\text { Did not prove to be an interesting feature } \\
\text { to examine }\end{array}$ \\
\hline Jerkiness & $0 / 14(0)$ & Always increasing when suppored \\
\hline Length & $9 / 14(0)$ & $\begin{array}{c}\text { No difference between guided writers } \\
\text { and suppored signatures }\end{array}$ \\
\hline Spacing & $14 / 14(1)$ & $\begin{array}{c}\text { No difference between guided writers } \\
\text { and suppored signatures }\end{array}$ \\
\hline Ratio & $14 / 14(1)$ & $\begin{array}{c}\text { No difference between guided writers } \\
\text { and suppored signatures }\end{array}$ \\
\hline Letter construction & $14 / 14(1)$ & $83 / 126(6 / 9)$ \\
\hline Total & $65.8 \%(66.6 \%)$ & \\
\hline
\end{tabular}

Figure 6. Common features of supported signatures with guided writers

\begin{tabular}{|l|c|c|}
\hline Feature & Matching subjects & Notes \\
\hline Slope & $14 / 14(1)$ & \\
\hline Size & $7 / 14(1)$ & $\begin{array}{r}\text { Bigger size on many guided signatures } \\
\text { than guider's specimens }\end{array}$ \\
\hline Fluency & $0 / 14(0)$ & \\
\hline Pen lifts & $6 / 14(1)$ & \\
\hline Jerkiness & $0 / 14(0)$ & \\
\hline Length & $9 / 14(0)$ & \\
\hline Spacing & $9 / 14(1)$ & \\
\hline Ratio & $14 / 14(1)$ & \\
\hline Letter construction & $14 / 14(1)$ & \\
\hline Total & $70 / 126(6 / 9)$ & \\
\hline
\end{tabular}

Figure 7. Grouping of results 


\section{Summary and conclusions}

The results were examined with the purpose of determining the extent to which the guider's features affect the signature of the guided writer when assisting him at signing. The statistical tests performed showed significant differences regarding the most prominent features; slope, letter construct, ratio and spacing, both in supported and guided signatures. The supported signatures had notably increased likelihood of being similar to the guided writers (14.2 times more likely).

Additionally, there was increased likelihood of the guided signatures exhibiting similar features to the guider's signatures (3.4 times).

It was confirmed that if the guided person is passive when guided, no creating impulses of his handwriting should be expected, as Hecker had previously observed.

It was also noted, that the size of the signatures was usually larger, the fluency of the writing worse and the jerkiness was increasing on the supported and guided signatures compared to the normal specimens of the guided and guider writers respectively.

There were significant differences detected in the features of slope, letter construction, ratio and spacing for both supported and guided signatures in almost all of the 14 subjects studied. Those differences revealed that many of the features in supported signatures belonged to the guided writer, while the guided signatures were portraying many features of the guider. This in turn provides good evidence that the features of the guider should be expected to dominate throughout a guided signature, which again comes in agreement with Hecker's observations.

The results were consistent and established a key difference regarding the supported and guided signatures that may have positive repercussions. The importance of these findings lies in the delineating of a scientific criterion which would allow document examiners to for a more confident opinion when examining guided signatures. 


\section{References}

Foley F.G., Kelly J.H, "Guided hand signature research”, Journal of Police Science and Administration, vol. 5, 1977.

Hecker M.R., "The taking of handwriting samples in relation to cases of claimed assistance in writing", Journal of Forensic Document Examination, vol. 2, 1988, no. 1-2.

Jones D.G., "Guided hand or forgery?", Journal of the Forensic Science Society, vol. 26, 1986.

Sellers C., "Assisted and guided signatures", The Journal of Criminal Law, Criminology and Police Science, vol. 53, 1962.

\section{Summary}

A study carried through to determine which writer's features are apparent in the end result of a guided signature. The examination included 14 participants in total, one of which was left handed. To fulfill its scope, 9 writing features of 20 supported and 20 guided signatures for each participant were examined and the results were related to previous research on the matter of guided signatures and handwriting. This study demonstrated that guided signatures yield a significant volume of writing features belonging to the guider, providing robust evidence on the subject of guided signatures. Several limitations were highlighted and proposals for future studies were also made.

Keywords: guided hand, assisted signature, supported signature, writing assistance. 